Experiencia educativa

\title{
El asociacionismo salesiano universitario como mecanismo de educación ciudadana
}

\author{
The university salesian fellowship as a way for citizen education \\ Roberto Alexander Damas * \\ roberto.damas@udb.edu.sv \\ ISSN 1996-1642, Editorial Universidad Don Bosco, año 8, No.14, Julio-Diciembre de 2014, pp.55-63 \\ Recibido el 16 de mayo de 2014. Aprobado el 1 de julio de 2014
}

\begin{abstract}
Resumen
El asociacionismo Universitario Salesiano es un mecanismo de empoderamiento del joven por medio de una educación en ciudadanía que lo prepara para su rol como hombre o mujer de bien, como un ciudadano o ciudadana en el tejido social. La experiencia de asociacionismo en la Universidad Don Bosco es la de un mecanismo concreto de participación para el joven que no solo le otorga espacio de participación, sino que fomenta su identidad. Con esto se genera una mejor percepción de la institucionalidad que funciona, que la organización es la mejor manera de participar para el logro del bien común y que la fe y la razón pueden estar en sinergia al servicio de las personas. Esto incide en la formación de un profesional diferente, un profesional humanizado y humanizante, que es consciente de su dignidad y la de las demás personas.
\end{abstract}

Palabras clave: asociacionismo, joven, educación, universidad, ciudadanía.
Abstract:

The university salesian fellowship is a mechanism for young students' empowerment through citizen education that enable them to act as a good man or woman, as a responsible citizen in society. The experience of association and fellowship at Universidad Don Bosco is that of a concrete mechanism of students' participation that does not only provide room but also foster their identity, generating in the process a better perception of the institution and that getting organized in common participation is the better way to achieve common wellbeing and that faith and reason can generate synergy for people. All this impinge on the formation of a different professional, one who is humanized and humanizing, that is conscious of his or her dignity and the dignity of others.

Keywords: fellowship, Young, education, university, citizenship

* El autor es Salesiano cooperador, Licenciado en Comunicación Social, maestrante del programa Políticas para la prevención de violencia juvenil en cultura de paz, periodista, locutor, docente y director de Pastoral Universitaria de la Universidad Don Bosco.

Para citar este artículo: Damas, R. A. (2014). El Asociacionismo Salesiano Universitario como mecanismo de educación ciudadana. Diálogos 14, 55-63. 
"El grupo de pastoral me ha enseñado que el cristianismo es acción, es actuar concretamente a favor de alguien, especialmente del que sufre, no es un espiritualismo estéril, es imitar a Jesús y como profesional que la sociedad espera un profesional con el conocimiento al servicio de las personas, y hacer un cambio en una sociedad que necesita a Jesús". Lourdes Torruella, Ingeniera biomédica

\section{Introducción}

Cuando se habla de jóvenes y juventud, o las juventudes, con frecuencia se define como una categoría social, como un ser biológico, o su comprensión desde la psicología, lo que provoca concepciones aisladas, ante una realidad muy compleja, pero a la vez concreta, en la cual a la dimensión espiritual se le resta importancia, eludiendo la evidencia empírica de que la mayor parte de jóvenes de El Salvador creen en Dios (FLACSO, 201 1; IUDOP, 2010; \& CONCULTURA, 2008) (FLACSO, IUDOP, \& CONCULTURA, 2011, 2010, 2008). Por ello en esta reflexión se encontrarán con un hecho educativo con un fondo teocéntrico cuyas implicaciones concretas se deben manifestar en la convivencia social.

Como jóvenes entenderemos para esta reflexión académica una persona entre los 15 a los 25 años, quien es sujeta de derechos y obligaciones como cualquier otra, quien debe también desarrollarse plenamente en la sociedad, en igualdad de oportunidades ante las relaciones de poder en su relación con los adultos. Es una persona con 4 dimensiones importantes: social, biológica, psicológica y espiritual, que determinan su manera concreta de ser persona, es decir joven.

\section{El asociacionismo como una experiencia educativa}

El Asociacionismo Salesiano Universitario (ASU) está anclado en el carisma mismo de los salesianos, es lo que diferencia a la Universidad Don Bosco de otras propuestas educativas de educación superior. Es algo único, se dedican recursos, personas y proyectos a acompañar y servir a los jóvenes en estos espacios asociativos.

El ASU es un espacio alternativo y formativo. Los jóvenes encuentran aquí un suelo firme para empezar con su construcción personal, que les sirve para su transformación, para asumir compromisos con ellos mismos, con la universidad y con su sociedad.

Se trata de un proyecto de vida, personal y grupal a la vez que expresa la vitalidad juvenil universitaria encausada por los grupos: culturales, deportivos,

El asociacionismo

salesiano universitario

como mecanismo de educación

56. ciudadana 


\section{La necesidad del grupo de la condición juvenil}

Desde su juventud Don Bosco instituyó esta necesidad de los jóvenes como una experiencia educativa para formarse como personas. En el desarrollo de su obra hubo algunas experiencias que habría que rescatar como significativas, por ejemplo las Compañías organizadas de acuerdo con el nivel y condición de los jóvenes: estudiantes, aprendices, muchachos que apenas comenzaban o ya maduros, tenía así la Compañía de San Luis para la mayoría de los jóvenes, la Compañía del Santísimo Sacramento, para los jóvenes escogidos más avanzados, de los cuales un sub grupo formaba el pequeño clero. Para líderes más seleccionados tenía la Compañía de la Inmaculada Concepción, que actuaba intencionalmente a favor de sus compañeros y en la transformación del ambiente'; tenían evaluaciones periódicas de su acción. Para los más adultos tenía la Conferencia de San Vicente y para los artesanos la Compañía de San José. Cada proceso asociativo estaba desagregado por la condición del muchacho y sus necesidades, claramente condicionado a la acción educativa y la mentalidad del sacerdote piamontés, quien por medio de estas asociaciones se apoyaba para garantizar el ambiente entre los jóvenes necesarios para su educación, el objetivo era generar terreno fértil.

Una experiencia asociativa que merece destacarse es "La Sociedad de Mutuo Socorro", para los jóvenes trabajadores, que se preocupaba de proteger a los socios desamparados o sin empleo (Scaramussa, 1996). Esta última experiencia nos evidencia la visión de asociacionismo de Don Bosco más allá de un limitado pietismo o simple grupo juvenil, las experiencias asociativas buscaban desarrollar principios, valores y actitudes hacia la vida en el joven, que le formarán como ciudadano para insertarse en el tejido social, preocupado del bien común y del bien particular como persona madura.

En una carta a los salesianos en 1873, exhortaba a sus educadores a no temer a la fundación de estas asociaciones:

Ninguno tenga temor de hacerlas, de recomendarlas, de favorecerlas y de exponer su finalidad, el origen las indulgencias y otras ventajas que ofrecen. Yo creo que las asociaciones pueden llamarse clave de piedad, defensa de la moralidad, y sustento de la formación de la vocación. (Epistolario 3, 7-8).

El asociacionismo juvenil ha sido y es parte de la pedagogía salesiana desde sus orígenes para lograr el binomio buenos cristianos y honestos ciudadanos; los elementos fundamentales son el cumplimiento del deber, la asunción de las propias obligaciones como camino de trascendencia; es decir, santidad y la práctica de la caridad y la solidaridad como militancia para transformar el propio ambiente, a manera de fermento.

1. En la actualidad este objeto del asociacionismo salesiano sigue siendo el mismo, y generando fecundamente los mismos frutos, con la diferencia de adecuar esta experiencia a las nuevas realidades y también a las nuevas obras, como es el caso de las universidades salesianas. 


\section{¿Cómo se organiza el asociacionismo ahora?}

El criterio básico y fundamental es el mismo: la libertad; nunca se obliga, ya que la participación es un acto voluntario del joven (Scaramussa, 1996), debido a que la coordinación y la conducción del grupo lo realizan los mismos jóvenes, este empoderamiento lo recomendó el mismo Don Bosco:

Las compañías deben recomendarse y promoverse. Pero ustedes solo serán promotores, no directores; consideren tales cosas de los muchachos, bajo asesoría del educador. (Amadei, 1993).

De esta manera el Asociacionismo Salesiano Universitario, genera un espacio real para el joven y su participación en la comunidad educativa que le educa en esta dimensión ciudadana, para comprender de manera micro la dimensión macro del bien común y el bien individual, al hacerse cargo de su propia autoformación y autogestión del conocimiento, al servicio de los demás y de la universidad.

El asociacionismo me ha enseñado a interactuar con las personas de diverso pensamiento y credo religioso, y reconocer el aporte de otras personas, a adquirir actitudes de liderazgo, y a sincronizar fe y razón. Ronald Marroquín, estudiante de Ingeniería mecánica.

El asociacionismo y la vida de grupo, en medio de una compleja sociedad posmoderna determinada por la fragmentación por medio de experiencias sociales y culturales de masificación y de anonimato (Binder, 1991), ofrecen al joven un espacio de reconocimiento y de afirmación de la subjetividad, y el del sentido unitario para la propia vida, el asociacionismo refuerza y respalda la participación de los jóvenes ante una sociedad adultocentrista ${ }^{2}$ (UNICEF, 2013) ya que sirve como espacio de comprensión de la sociedad, de preparación para insertar al joven de forma activa y transformadora en su contexto, de ejercicio para mantener la autonomía personal y el equilibrio en medio de los conflictos.

El ASU contribuye también en la aceptación del joven de sí mismo y a la vez para afirmar la propia personalidad, la experiencia de grupo en las asociaciones ofrece oportunidad de confrontaciones que desenvuelven y maduran la identidad personal, responden a la necesidad de valoración, de aprobación de prestigio, y estimulan el sentido de autenticidad.

El asociacionismo salesiano universitario como mecanismo de educación

58. ciudadana
2. Adultocentrismo: indica que existen relaciones de poder entre los diferentes grupos de edad que son asimétricas en favor de los adultos, es decir, que estos se ubican en una posición de superioridad. Los adultos gozan de privilegios por el solo hecho de ser adultos, porque la sociedad y su cultura así lo han definido. Por ejemplo, si un adolescente rompe un vidrio por error, recibe una sanción de parte del adulto (grito, reto, castigo o golpes), si este adulto comete el mismo error, no recibe castigo de parte del adolescente e incluso puede asumir que fue un accidente y, en el mejor de los casos, decir que tiene derecho a equivocarse. 
Me ha ayudado a vencer el miedo a hablar en público, y adquirir la confianza y seguridad, de que las cosas que realizo en la asociación de biomédica, son con la única intención de ayudar a mis compañeros. Wilfredo Aparicio estudiante de Ingeniería biomédica.

El asumir progresivamente varias funciones por parte del joven dentro de la estructura asociativa, le permiten experimentar su capacidad de responsabilidad. Las posibilidades de comunicación que la experiencia asociativa le ofrece le ayudan a abrirse a los demás, a relacionarse con el otro, a vivir la "alteridad". El ASU responde a las necesidades de formación y crecimiento, el grupo es el lugar primario de toma de conciencia de la propia existencia en la sociedad. Desarrolla el sentido de libertad, de autonomía personal y al mismo tiempo de solidaridad con el prójimo y con la humanidad en general, es decir le humaniza. Capacita para la realización del propio proyecto de vida, ayuda a purificar y a vivenciar la fe, ya que los jóvenes tienen dificultad en expresar la fe en formas rígidas o formales que generalmente predominan en las iglesias, el asociacionismo ofrece mayor espacio de aproximación, de reflexión a partir de los problemas que los jóvenes están viviendo ${ }^{3}$, de celebración más libre y viva de la propia vida en la fe.

Uno de los estudiantes de la Asociación de Estudiantes Salesianos en Pensamiento y Educación Ciudadana de la universidad manifiesta lo siguiente, en cuanto a su experiencia asociativa:

Me ha servido para dejar de pensar en mí mismo, convivir con las demás personas y ser más humano. Alberto Castillo, estudiante de Licenciatura en diseño gráfico.

\section{Asociacionismo y cultura ciudadana}

La juventud en la actualidad manifiesta poco interés en la "política de partido" debido a la falta de credibilidad en los protagonistas de la misma; solamente un 19.3\% de los jóvenes están interesados en la política (Zetino y Brioso, 2013), lo que mina la disposición a la participación ciudadana para una reestructuración social, sumado a una visión adultocentrista que no facilita los espacios de participación de los jóvenes, y cuyos mecanismos de dicha participación, son inapropiados o inexistentes 4 . La mayoría de los jóvenes de El Salvador creen que la solución política estriba en el retorno de los militares al poder y el gobierno (el

3. Un ejemplo claro es el voluntariado universitario salesiano, que procura contextualizar el conocimiento en el sufrimiento de los demás, y como este debería servir para aliviarlo, ejercitando la caridad evangélica al servicio de los pobres, así como las reuniones de los consejos de las asociaciones con las autoridades de la UDB, para el involucramiento en la solución de los problemas académicos, administrativos y educativos, que les atañen como estudiantes, a la vez de proponer proyectos e iniciativas que mejoran el ambiente educativo y el espíritu de familia.

4. Por ejemplo las juventudes de los partidos políticos no poseen el mecanismo de participación apropiado para que los jóvenes puedan incidir en el rumbo y la toma de decisiones de sus institutos políticos, y así podríamos también enumerar otras instituciones con la misma deficiencia. 
$52 \%$ de los jóvenes considera que para solucionar los problemas de violencia es necesario que los sectores militares estén a cargo del gobierno), y que la tolerancia se da cuando se piensa de igual manera, lo que denota una muy clara "cultura autoritaria", aún no superada. Un 92\% considera que las leyes deben ser endurecidas; un $61 \%$ cree necesaria la implementación de la pena de muerte; y un $36 \%$ piensa que los ciudadanos deben hacer justicia por "su propia mano", según Larissa Brioso investigadora de FLACSO.

Pero esta visión no es propia de la condición juvenil, el Dr. Mario Zetino, sociólogo, consultor de FLACSO, y profesor de la Universidad Don Bosco afirma en una de sus investigaciones más recientes que es la visión de "toda la sociedad", que los adultos heredan esta condición de generación en generación y que se trasmite de forma intergeneracional a los jóvenes.

Estamos ante una "emergencia educativa", los procesos educativos no ha incluido la educación en ciudadanía, por ello el Asociacionismo Salesiano Universitario se vuelve un mecanismo eficaz para educar salesianamente al joven en su dimensión ciudadana como un actor relevante y protagónico del tejido social, con los valores y competencias anteriormente mencionados (Salesianos, Centroamérica, 1992). "A mayor nivel de escolaridad mayor es la probabilidad de que se involucren en la política" (Zetino y Brioso, 2013). Los jóvenes con escolaridad básica tienen 32 veces mayores posibilidades de no participar en política que aquellos que tienen escolaridad superior, lo cual hace que la educación superior sea un terreno fértil para la educación en ciudadanía.

\section{El asociacionismo en la Universidad Don Bosco}

Siete de cada 10 jóvenes afirman formar parte de alguna organización, el 44.6\% de éstas son instituciones religiosas, mientras que solo el $7 \%$ en organizaciones políticas (Zetino y Brioso, 2013), la razón fundamental es el deseo concreto de hacer algo de provecho y de ayuda para los demás como la condición de la participación juvenil en cualquier aspecto (Ramos, Montoya, Alas, Cabrera y Benítez, 2011); es decir, los jóvenes creen que su participación debe ser significativa. Pero otra razón por la cual los jóvenes no participan es la falta de credibilidad en las instituciones ${ }^{5}$, ya que no se ven representados ni como parte de ellas (Tablas y Zepeda, 2011 ), la debilidad institucional que garantiza el funcionamiento y ordenamiento social es percibida por los y las jóvenes como ineficaz, lo que provoca su apatía a la participación ciudadana.

En la Universidad Don Bosco, desde el modelo educativo salesiano, se ha desarrollado un mecanismo para que cada asociación de estudiantes

El asociacionismo salesiano universitario como mecanismo de educación

60. ciudadana
5. No solamente las instituciones estatales, sino en las que se desarrollan, universidades, colegios, iglesias, etc. 
protagonismo y participación concreta en el desarrollo del proceso enseñanza aprendizaje en el que se desarrolla.

Las asociaciones universitarias tienen su propio gobierno, que es estructurado y animado por los mismos estudiantes, en donde los educadores solo somos acompañantes de la experiencia y no directores de dicho proceso, lo que permite una participación significativa y real de los jóvenes universitarios, y la concreción de la experiencia asociativa se da en los siguientes aspectos:

- Académico-Científico

- Voluntariado

- Evangelización

- Cultural y Artístico

- Deportivo

Las tres primeras iniciativas asociaciativas están bajo la animación del Departamento de Pastoral Universitaria, la cultural y artística por el departamento de Arte y Cultura y la deportiva por el departamento de Asistencia Estudiantil. Las asociaciones, grupos deportivos y culturales suman más de veinte, con un aproximado de 400 jóvenes involucrados en alguna iniciativa asociativa, de las que el Centro de Desarrollo Integral Universitario (CDIU), propone a la comunidad estudiantil, siendo este a la vez no solo un espacio social, sino también físico en el cual los estudiantes concretizan su participación. La comunidad se configura en sintonía con los valores del humanismo cristiano y del carisma salesiano, indicados en el Proyecto Institucional. Como se observa en la Ex Corde Ecclesiae, la fuente de su unidad brota de la común consagración a la verdad, de la misma visión de la dignidad humana y, en último análisis, de la persona y del mensaje de Cristo (Attard, 2014).

La responsabilidad, el liderazgo, la tolerancia, el diálogo, la amabilidad, el ambiente de familia, el trabajo en equipo, el reconocimiento de derechos y obligaciones, la noción de bien común, la gratuidad, son algunos de los valores que se traducen en competencias que complementan la formación académica del joven y le dan identidad con la institución formando su dimensión ciudadana.

Un ejercicio que ha sido de mucho provecho, son las reuniones periódicas con las autoridades de la Universidad y las asociaciones estudiantiles permiten, en un clima de confianza y respeto, propios del ambiente salesiano de familia, que los jóvenes expresen sus propuestas, iniciativas, y sus inconformidades para con la Universidad y que se traducen en un cambio concreto que los jóvenes pueden percibir; al mismo tiempo es el espacio donde las autoridades también transmiten las posturas institucionales a los jóvenes organizados en las 
asociaciones para difundir la información pertinente y de interés de manera directa, que a la vez es difundida por los mismos estudiantes ${ }^{6}$.

El hecho de organizarse le trae al joven beneficios como ser tomado en cuenta para representaciones institucionales, en procesos, eventos, foros o capacitaciones, dentro o fuera de la institución, representar a sus compañeros y compañeras, tener un acercamiento libre y directo con las autoridades, en un clima de afabilidad, respeto y confianza, lo que le dignifica como persona, y le hacer reconocerse a sí mismo y los demás como tal.

La experiencia asociativa me ha enseñado a poner en práctica la sinergia, para desarrollar las actividades de autoformación académica y técnica, complementaria para una educación integral". Javier Castillo estudiante de Ingeniería eléctrica.

\section{A manera de conclusión}

El asociacionismo Universitario Salesiano previene al joven de caer en la lógica de sustituir su dimensión ciudadana por la de consumo (García, 1991) abriéndole a posibilidades de organización y participación ciudadana, más allá de la experiencia universitaria, en sus ambientes fuera del campus, como su colonia, iglesia, u otras experiencias de grupo y también como profesional una vez graduado de la universidad en el ambiente laboral.

En la pedagogía salesiana el asociacionismo es una intervención educativa que, al igual que Cicerón, traduce la paidea como humanitas, es decir, esa experiencia que humaniza, que no solo fomenta el rigor científico y la calidad académica, sino que vuelve al joven cada vez más persona.

El Asociacionismo Salesiano Universitario permite al joven plantearse la vida como proyecto, a corto, mediano y largo plazo, de crear una familia, de una opción vocacional, de "trascender" de forma integral, en una madurez no solo humana sino espiritual, que le provoca ser una persona a la altura de Jesús de Nazaret, lo que le vuelve un evangelizador en la práctica y no en el discurso, por medio de su testimonio en el respeto por la libertad, el gusto por la creación y la superación, la racionalidad frente a un universo por conocer y aprovechar, el emprendimiento, la búsqueda de la excelencia, la aptitud para servir al bien común por medio de un trabajo honesto y competente y con la concepción de la persona creada a imagen de Dios (Chávez, 2011).

La experiencia del asociacionismo no solo previene de las relaciones frías

El asociacionismo

salesiano universitario

como mecanismo de educación

62. ciudadana del mal uso de las TIC en muchos jóvenes de hoy como la incomunicación,

6. Un dato importante de mencionar de esta experiencia educativa, es que a partir de estas reuniones con las autoridades, los "memes" disminuyeron significativamente, debido al efecto de fermento en la masa de las asociaciones que intervenían en su grupo etario aclarando o explicando procesos desde su identidad institucional. 
aislamiento, silencio, fragmentación y ruptura de las relaciones (Vecchi, 2001), por medio de una comunicación cercana, interpersonal y más humana, que utiliza estas tecnologías como lo que son "herramientas", que no deben sustituir la humanidad de las relaciones entre las personas.

Podemos afirmar entonces que la experiencia pedagógica del asociacionismo en los jóvenes les empodera a descubrir su rol dentro del tejido social, a buscar la sinergia entre fe y razón, para ejercer un profesionalismo con un alto sentido de humanismo y un sólido compromiso social y político en la sociedad. Eso es lo que obedece al binomio heredado por Don Bosco: buenos cristianos y honestos ciudadanos".

\section{Referencias}

Amadei, Á. (1939). Memorias Biográficas, Tomo X. Turín: CCS.

Attard, F. (2014). La Pastoral Juvenil Salesiana: Cuadro de Referencia. Turín: Editorial S.D.B.

Binder, A. (1991). La Sociedad Fragmentada. Caracas.

Chávez, P. (2011). Educación y Ciudadanía Formar salesianamente al Ciudadano. San Salvador: Universidad Don Bosco.

FLACSO, IUDOP, \& CONCULTURA. (2011, 2010, 2008). Prácticas, Identidades y exectativas juveniles a inicios del siglo XXl; Encuesta nacional de juventud; adolescentes con cultura. San Salvador: FLACSO, UCA, DPI.

García, N. (1991). Consumidores y ciudadanos. Diálogos de comunicación.

Salesianos, Centroamérica (1992). Seminario sobre la educación a la democracia. San Salvador: Centro salesiano de pastoral.

Scaramussa, T. (1996). El sistema preventivo de Don Bosco. San Salvador:UDB

Tablas, V. y Zepeda, M. (2011). Diagnóstico de situación de la población joven de El Salvador. San Salvador: Fundaungo.

UNICEF. (2013). Superando el adultocentrismo. Santiago de Chile: ONU.

Vecchi, J. (2001). Guardianes de sueños. Turín: ELLEDICl.

Zetino, M. y Brioso, L. (2013). Jóvenes urbanos. Cultura política y democracia de posconflicto en Centroamérica. San Salvador: FLACSO. 